\title{
Myocardial Tissue Perfusion Predicts the Evolution of Fragmented QRS in Patients with ST-Segment Elevation Myocardial Infarction Undergoing Primary Percutaneous Coronary Intervention
}

\author{
Firat Ozcan, M.D., Osman Turak, M.D., Uğur Canpolat, M.D., \\ İskender Kadife, M.D., Sedat Avci, M.D., Ahmet Işleyen, M.D., \\ Muhammed Cebeci, M.D., Özgül Malçok Gürel, M.D., Fatma Nurcan Başar, M.D., \\ Derya Tok, M.D., Serkan Topaloğlu, M.D., Dursun Aras, M.D., \\ and Sinan Aydoğdu, M.D.
}

From the Cardiology Clinic, Türkiye Yüksek Ihtisas Training and Research Hospital, Ankara, Turkey

Background: Fragmented QRS complex (fQRS) is associated with worse outcomes in several cardiovascular conditions. However, alterations in fQRS in patients with ST elevation myocardial infarction (STEMI) who underwent primary percutaneous coronary intervention $(\mathrm{PCl})$ and association of fQRS with myocardial blush grade (MBG) has not been investigated until now. In this study, we aimed to investigate the association of MBG after primary $\mathrm{PCI}$ with evolution of $\mathrm{fQRS}$.

Methods: Our study consisted of 401 consecutive patients with STEMI who underwent primary $\mathrm{PCl}$. Patients were categorized into two subgroups according to persistence or new-onset of fQRS (Group 1) and absence or resolution of fQRS (Group 2) at 48 hours after primary PCI. The evolution of $\mathrm{fQRS}$ on pre- and post-PCI ECG and their relation with myocardial reperfusion parameters were investigated.

Results: Patients in group 1 showed older age, higher rate of smoking, lower HDL-cholesterol, lower LVEF, higher angina-to-door time, higher TIMI frame count, and high rate of patients with MBG $<3$ compared to patients with group $2(\mathrm{P}<0.05)$. In correlation analysis, LVEF showed positive correlation with MBG $(r=0.448, \mathrm{P}<0.001)$ and negative correlation with the number of leads with $\mathrm{fQRS}(\mathrm{r}=-0.335, \mathrm{P}<0.001)$. In multivariate regression analysis, new-onset or persistance of $\mathrm{fQRS}$ after primary $\mathrm{PCI}$ is significantly associated with $\mathrm{MBG}<3$, peak CK-MB level, pre-PCI fQRS at anterior localization and smoking.

Conclusion: Our findings showed that despite complete ST-segment resolution in all patients, fQRS is independently associated with impaired microvascular myocardial perfusion. So, fQRS, as a simple and easily available noninvasive marker, may be useful in stratification of high-risk patients with increased extent of infarcted myocardium who underwent primary PCI.

Ann Noninvasive Electrocardiol 2014;19(5):454-461

fragmented QRS; electrocardiography; myocardial infarction; reperfusion

\section{INTRODUCTION}

Coronary reperfusion therapy both with fibrinolytics and primary percutaneous coronary intervention (PCI) aims to improve myocardial perfusion in patients with ST-segment elevation myocardial infarction (STEMI). ${ }^{1,2}$ Successful reperfusion predicts the early and long-term

Address for correspondence: Uğur Canpolat, M.D., Cardiology Clinic, Türkiye Yüksek Ihtisas Training and Research Hospital, Sihhiye 06100, Ankara,Turkey.Fax: +90 312306 1134; E-mail:dru_canpolat@yahoo.com

This study was not funded by any institution. Authors do not have any conflict of interest. 
survival. ${ }^{2}$ So, several prognostic parameters have been developed to predict adverse cardiovascular outcomes in patients undergoing primary PCI. ${ }^{3}$ Myocardial blush grade (MBG) is one of the simplest and available parameter which provides visual assessment of myocardial perfusion during coronary angiography. It represents the myocardial microvascular circulation. Previous reports revealed that higher MBG was associated with ST-segment resolution, improved left ventricular systolic function and long-term mortality. ${ }^{4-7}$

Fragmented QRS complex (fQRS) on standard electrocardiography (ECG) reflects myocardial perfusion defect with nuclear imaging and/or myocardial scarring with cardiac magnetic resonance imaging (MRI)..$^{8-12}$ It has been shown that fQRS was associated with or predictor of adverse cardiovascular events in patients with coronary artery disease (CAD). ${ }^{9,13,14}$ Also, development of fQRS complex during acute coronary syndrome and its long-term prognostic importance were investigated in several studies. However, alterations in fQRS in patients with STEMI who underwent primary PCI and association of fQRS with MBG has not been investigated previously. In this study, we aimed to investigate the association of MBG after primary PCI with evolution of fQRS.

\section{METHODS}

\section{Study Population}

In this prospective and observational study, a total of 401 consecutive patients with STEMI who admitted $<6$ hours from symptom onset to our emergency room and underwent primary PCI were enrolled between November 2010 and March 2012. Patients with severe primary valvular heart disease, on-admission cardiopulmonary arrest, bundle branch block (LBBB, incomplete or complete RBBB or duration $\mathrm{QRS}>120 \mathrm{~ms}$ ), previous known history of CAD, and those with permanent pacemakers were excluded from the study. Patients were categorized into two subgroups according to persistence or new-onset of fQRS (Group 1) and absence or resolution of fQRS (Group 2) at 48 hours after primary PCI. Informed consent was taken from each patient before enrollment. The study was in compliance with the principles outlined in the Declaration of Helsinki and approved by Institutional Ethics Committee.

\section{DEFINITIONS}

Clinical characteristics and current cardiovascular medication use were provided from each patient at the time of clinical consultation. Blood pressure was obtained in a sitting position after 5 minutes and hypertension was defined as a diastolic blood pressure $\geq 90 \mathrm{mmHg}$ or a systolic blood pressure $\geq 140 \mathrm{mmHg}$ or the self-reported use of antihypertensive drug(s). Diabetes mellitus (DM) was diagnosed in case of a history of oral antidiabetic, insulin medication or fasting blood glucose $\geq 126 \mathrm{mg} / \mathrm{dL}$ at study entrance. Patients who were smoking or quit smoking within the last year were considered as smokers. A family history of premature CAD was defined as CAD in a parent or sibling diagnosed under the age of 55 for men and 65 for women.

Acute STEMI was diagnosed according to an ECG obtained during admission to emergency room in the presence of related symptoms and findings. Patients with typical chest pain and with the presence of new or presumed new ST-segment elevation at the $\mathrm{J}$ point in $\geq 2$ contiguous leads of $\geq 2 \mathrm{~mm}$ in leads $\mathrm{V}_{1}, \mathrm{~V}_{2}$, or $\mathrm{V}_{3}$ and $\geq 1 \mathrm{~mm}$ in other leads. Marked ST depression, which was maximal in leads $\mathrm{V}_{1-3}$, without ST-segment elevation in other leads, was designated as posterior wall MI. ${ }^{15}$ We recorded all ECGs on-admission and at 48 hours after primary PCI. We defined fQRS on the routine 12-lead ECG (filter range $0.15-100 \mathrm{~Hz}$, AC filter $60 \mathrm{~Hz}, 25 \mathrm{~mm} / \mathrm{s}, 10 \mathrm{~mm} / \mathrm{mV}$ ), which includes various morphologies of the QRS wave with or without a $Q$ wave. fQRS includes the presence of an additional $R$ wave $\left(R^{\prime}\right)$ or notching in the nadir of the $\mathrm{R}$ wave or the $\mathrm{S}$ wave, or the presence of more than one $\mathrm{R}^{\prime}$ (fragmentation) in two contiguous leads, corresponding to a major coronary artery territory. ${ }^{13}$ Two investigators evaluated the ECG of the patients for the presence of $f Q R S$. The territories for defining the location of fragmentation mentioned as follows; anterior (V15), inferior (DII-III-aVF) and lateral (DI-aVL-V6).

\section{CORONARY ANGIOGRAPHY AND PERCUTANEOUS CORONARY INTERVENTION}

Our hospital is a high volume tertiary cardiology center with 24 hours/7 days PCI facility and experienced interventional cardiology staff. Any 


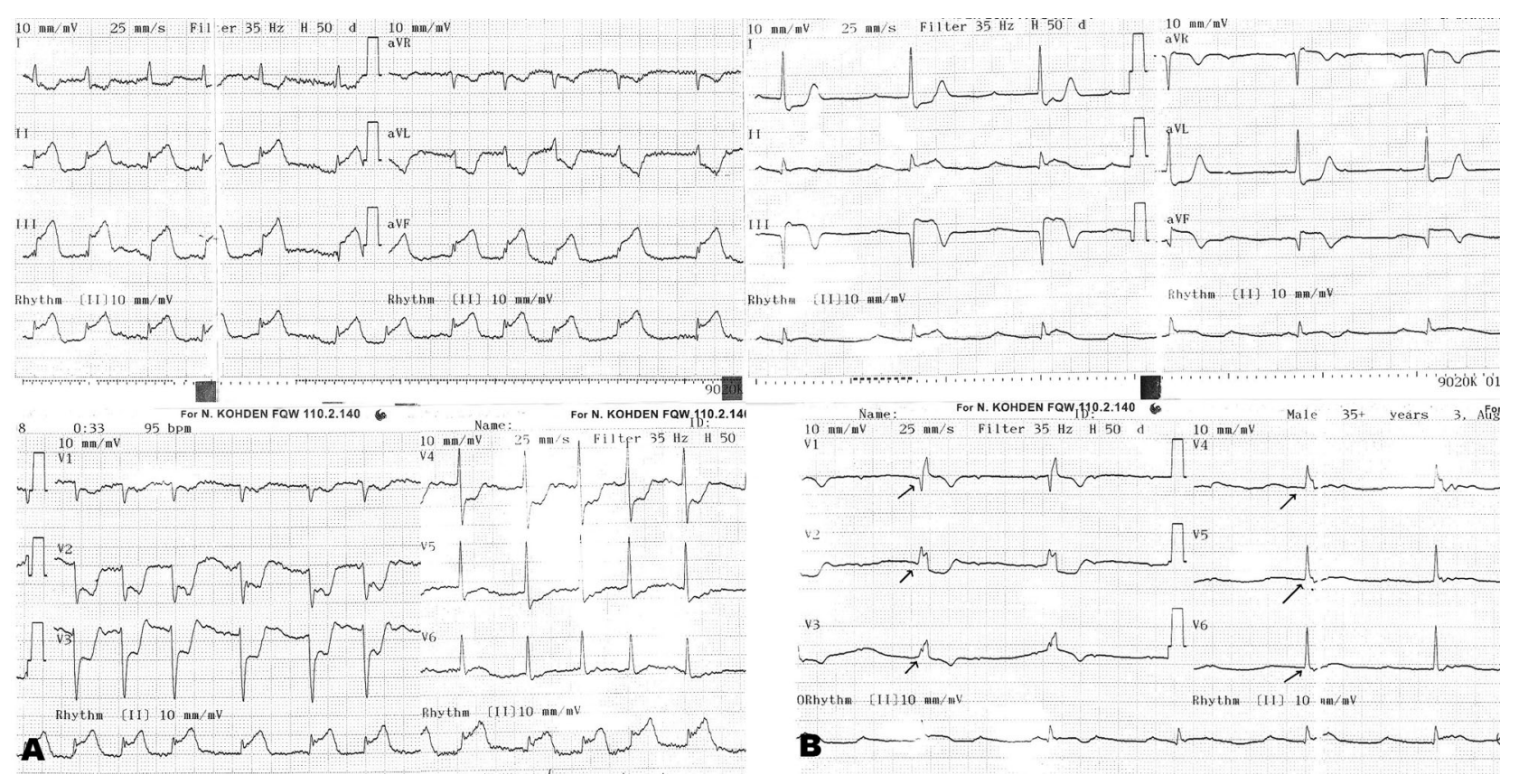

Figure 1. A 48-year-old female patient admitted to our emergency room with squeezing chest pain for 4 hours. On admission electrocardiography (ECG) showed 5-mm ST-segment elevation at inferior derivations (II, III, aVF) with no fQRS complex (A). She has been transferred to cath laboratory for primary $\mathrm{PCl}$ and totally occluded right coronary artery (RCA) was revascularized with balloon dilatation and stenting (TIMI III flow, TIMI FC: 30 ms, MBG = 1). Post-PCI ECG showed 3-mm ST-segment elevation at inferior derivations with fQRS complex at all precordial derivations (6 leads).

$\mathrm{FC}=$ frame count; $\mathrm{MBG}=$ myocardial blush grade; $\mathrm{PCl}=$ percutaneous coronary intervention.

patient who admitted with chest pain to our emergency department, is welcomed by a cardiology specialist. Premedication is given immediately at the emergency department, and the patients are admitted to the catheterization laboratory, which is located on the upper floor of the emergency department. Average door to balloon time is $<30$ minutes. Coronary angiography followed by PCI was performed to achieve normal blood flow for infarct related artery (IRA). Primary PCI was performed with the conventional technique. The other stenotic coronary arteries were not targeted for intervention unless cardiogenic shock emerged. The procedural decisions like device selection and other adjunctive pharmacotherapy were made at the discretion of the individual PCI operator. Intravenous unfractionated heparin $100 \mathrm{IU} / \mathrm{kg}$ before PCI was given with $600 \mathrm{mg}$ clopidogrel and $300 \mathrm{mg}$ aspirin. After stent implantation, angiographic optimization was performed by highpressure dilatation to achieve an acceptable angiographic result. Procedural success was defined as a residual stenosis of $<20 \%$ without major complications (i.e., stent thrombosis, need for emergent coronary artery bypass surgery or repeat PCI, coronary dissection or rupture and death).

The corrected thrombolysis in myocardial infarction (TIMI) frame count (CTFC) is the number of cine frames required for the contrast to first reach the standardized distal coronary landmarks in the culprit artery and was measured by use of a frame counter on a cine viewer. A frame count of 100 , a value that is the 99th percentile of patent vessels, was imputed to an occluded vessel. The cTFC is a measure of time, based on a filming speed of 25 frames/s. Definitions of the first and last frames used for TIMI frame counting are based on previous studies. ${ }^{16,17}$

The MBG was determined by the contrast density in an angiographic projection that isolated the distal myocardial region of the IRA. Grading was performed on cine film at 25 frames/s recorded in a digital coronary imaging catheterization laboratory. In each patient, the best projection was selected to assess the myocardial region perfused by the IRA. The duration of cine filming was required 


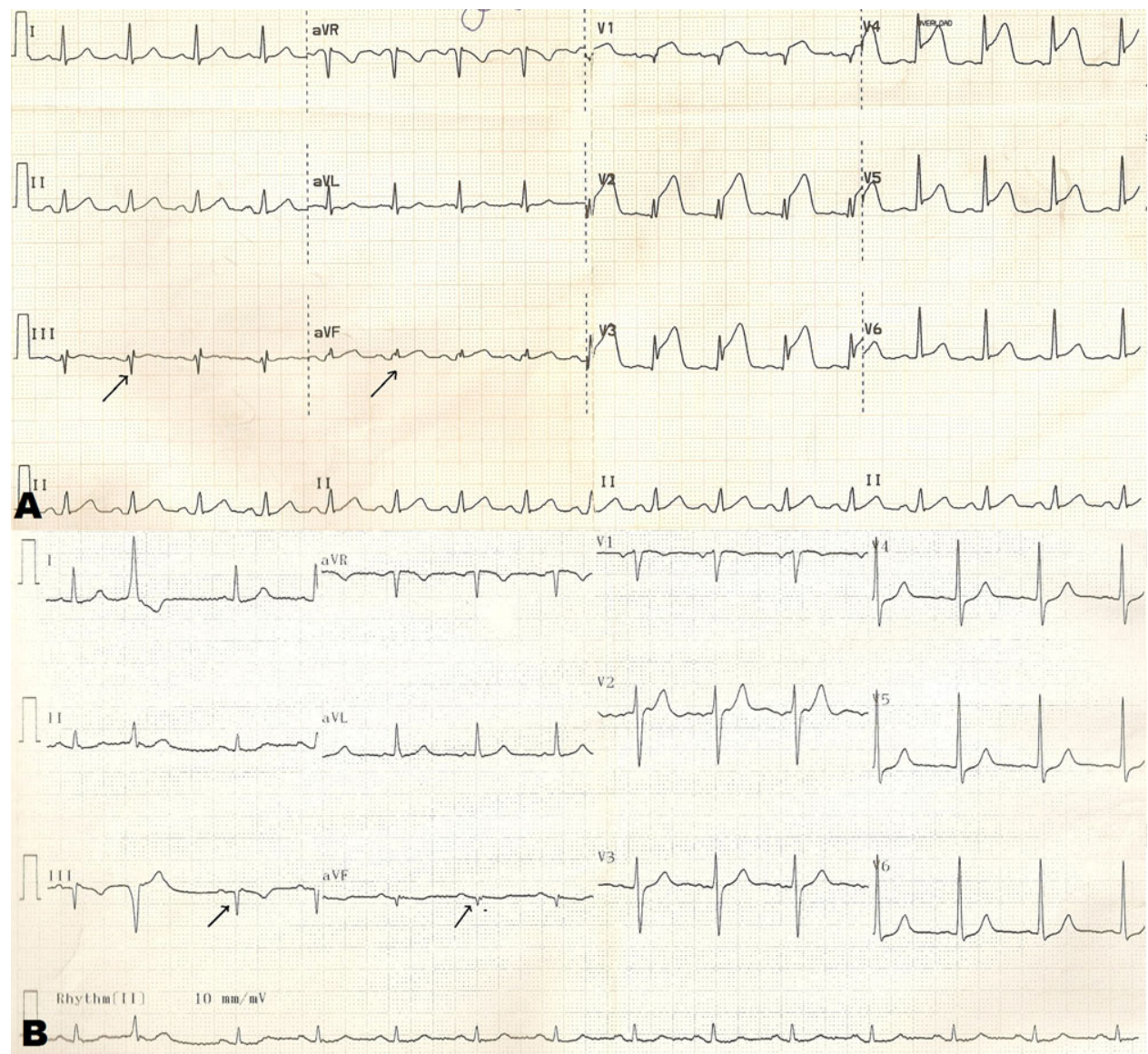

Figure 2. A 54-year-old male patient presented with chest pain for 25 minutes. On admission ECG revealed 6-mm ST-segment elevation at $V_{1-5}$ derivations with fQRS complex at III and aVF derivations (2 leads) (A). Primary PCI was performed for totally occluded left anterior descending artery (LAD) (TIMI III flow, TIMI FC: 15 ms, MBG = 3). Post-PCI ECG revealed isoelectric ST-segment at all precordial leads with fQRS complex at III and aVF derivations (2 leads) (B).

to exceed three cardiac cycles in the washout phase to assess washout of the myocardial blush. TIMI myocardial perfusion grades were assessed according to the previous definitions. ${ }^{18}$ Detailed description of the angiographic requirements to assess the MBG has been published previously by van't Hof et al. ${ }^{5}$ as; MBG of the myocardial infarct region was classified as 0: no myocardial blush, 1: minimal myocardial blush, 2: moderate myocardial blush, or 3: normal myocardial blush, all compared with the MBG of myocardial regions of non-IRAs. ${ }^{9}$ Two cardiologists who were blinded to each other and to the clinical data carried out the analysis.

Figures 1 and 2 represent the examples of ECGs with fQRS complex that were recorded on admission and after primary PCI.

\section{STATISTICAL ANALYSIS}

Continuous variables were expressed as mean \pm $\mathrm{SD}$ or median (interquartle range) and categorical variables were expressed as percentages. Continuous variables were tested for normal distribution by the Kolmogorov-Smirnov test. Categorical variables were analyzed by chi-square test or Fisher's exact test. Comparisons of continuous variables between the two groups were performed using the Student's t-test. Linear regression analysis with the stepwise method were used for the multivariate analysis of independent variables, which were included if they were significantly different in the univariate analyses. All tests with regards to significance were two-tailed. Statistical analyses were performed using SPSS statistical software 
458 • A.N.E. • September 2014 • Vol. 19, No. 5 • Ozcan, et al. • fQRS and MBG in STEMI

Table 1. Patient Characteristics According to Post-PCI Electrocardiographic fQRS Status

\begin{tabular}{|c|c|c|c|}
\hline & $\begin{array}{l}\text { Persistence or New Onset } \\
\text { of fQRS } n=130\end{array}$ & $\begin{array}{l}\text { Absence or Resolution } \\
\text { of fQRS } n=271\end{array}$ & $\mathbf{P}$ \\
\hline Age (year) & $55.9 \pm 11$ & $53.2 \pm 10.7$ & 0.044 \\
\hline Sex (male) & $107(82 \%)$ & $229(85 \%)$ & 0.577 \\
\hline $\mathrm{BMI}\left(\mathrm{kg} / \mathrm{m}^{2}\right)$ & $27.3 \pm 4$ & $26.8 \pm 4.1$ & 0.282 \\
\hline Hypertension (\%) & $42(32 \%)$ & $87(32 \%)$ & 0.967 \\
\hline Diabetes (\%) & $22(17 \%)$ & $36(13 \%)$ & 0.332 \\
\hline Smoking (\%) & 77 (59\%) & $108(40 \%)$ & $<0.001$ \\
\hline Family history of CAD (\%) & $50(39 \%)$ & $126(47 \%)$ & 0.129 \\
\hline SBP (mmHg) & $132.7 \pm 19.1$ & $129.3 \pm 19.6$ & 0.107 \\
\hline DBP (mmHg) & $82.6 \pm 11.4$ & $81.2 \pm 10.5$ & 0.262 \\
\hline Glucose (mg/dL) & $135.9 \pm 23.5$ & $125.4 \pm 24.9$ & 0.061 \\
\hline Creatinine $(\mathrm{mg} / \mathrm{dL})$ & $0.83(0.7-0.96)$ & $0.82(0.7-0.93)$ & 0.611 \\
\hline LDL-C (mg/dL) & $123.2 \pm 23.6$ & $121.3 \pm 22.8$ & 0.455 \\
\hline HDL-C (mg/dL) & $39.7 \pm 5.2$ & $42.2 \pm 4.9$ & $<0.001$ \\
\hline Triglyceride (mg/dL) & $150.1 \pm 33.9$ & $148.7 \pm 31$ & 0.696 \\
\hline WBC $\left(10^{3} u L\right)$ & $12.5 \pm 3.2$ & $12.2 \pm 3$ & 0.510 \\
\hline Hemoglobin $(\mathrm{g} / \mathrm{dL})$ & $13.8 \pm 1.7$ & $13.9 \pm 1.5$ & 0.579 \\
\hline Platelet $\left(10^{3} \mathrm{uL}\right)$ & $253.4 \pm 49.2$ & $256 \pm 46.3$ & 0.728 \\
\hline Peak CK-MB (U/L) & $237(146-346)$ & $137(75-242)$ & $<0.001$ \\
\hline LVEF (\%) & $43.6 \pm 6.2$ & $49.7 \pm 6.5$ & $<0.001$ \\
\hline TIMI FC & $29.4 \pm 11.7$ & $20.8 \pm 9.5$ & $<0.001$ \\
\hline Number of leads with ST-elevation & $5(3-6)$ & $3(3-5)$ & 0.001 \\
\hline $\begin{array}{l}\text { TQRS Iocallzation on aamission } \\
\text { Anterior }\end{array}$ & $71(55 \%)$ & $114(42 \%)$ & 0.018 \\
\hline Nonanterior & $59(45 \%)$ & $157(58 \%)$ & 0.018 \\
\hline Presence of fORS on admission & $81(62 \%)$ & $157(58 \%)$ & 0.404 \\
\hline $\mathrm{MBG}<3$ & $113(87 \%)$ & $109(40 \%)$ & $<0.001$ \\
\hline$M B G=3$ & $17(13 \%)$ & $162(60 \%)$ & $<0.001$ \\
\hline Angina-to-door time (hours) & $3.1 \pm 1.0$ & $2.3 \pm 0.9$ & $<0.001$ \\
\hline Stent length $(\mathrm{mm})$ & $24.2 \pm 8.1$ & $22.4 \pm 7.0$ & 0.065 \\
\hline Stent diameter $(\mathrm{mm})$ & $3.09 \pm 0.4$ & $3.15 \pm 0.5$ & 0.144 \\
\hline
\end{tabular}

$\mathrm{BMI}=$ body mass index; $\mathrm{CAD}=$ coronary artery disease; $\mathrm{SBP}=$ sytolic blood pressure; $\mathrm{DBP}=$ diastolic blood bressure; $\mathrm{LDL}=$ low-density lipoprotein; HDL = high density lipoprotein; LVEF = left ventricular ejection fraction; MBG = myocardial blush grade; TIMI FC = thrombolysis in myocardial infarction frame count of infarct related artery; WBC $=$ white blood cell count.

Angina-to-door time: the duration between the onset of chest pain and hospital arrival.

(version 20.0; SPSS Inc., Chicago, IL, USA). A P value $<0.05$ was considered statistically significant.

\section{RESULTS}

Baseline characteristics of both Groups 1 and 2 were presented in Table 1 . Patients with persistent or new-onset fQRS after primary PCI showed older age, higher rate of smoking, lower HDL-cholesterol, and also lower LVEF compared to patients with absence or resolution of fQRS after primary PCI $(\mathrm{P}<0.05)$. Among all study population, $46.1 \%$ of patients had anterior STEMI (55\% of Group 1 vs $42 \%$ of Group 2, P $=0.018$ ) and remaining had nonanterior STEMI.

The time from the onset of symptoms to hospital admission (angina-to-door time) was higher in
Group 1 compared to Group $2(3.1 \pm 1.0$ hours vs $2.3 \pm 0.9$ hours, $\mathrm{P}<0.001)$. Mean door to balloon time was $21.7 \pm 5.4$ minutes for all study group. Coronary angiographic data revaled similar stent size and length between two groups. However, Group 1 showed higher TIMI FC and high rate of patients with $M B G<3(P<0.001)$. STsegment resolution was achieved after primary PCI in all patients. In Spearman's correlation analysis, LVEF showed positive correlation with MBG $(\mathrm{r}=0.448, \mathrm{P}<0.001)$ and negative correlation with the number of leads with fQRS $(\mathrm{r}=$ $-0.335, \mathrm{P}<0.001)$. In univariate and multivariate regression analysis, new-onset or persistance of fQRS after primary PCI is significantly associated with MBG <3, peak CKMB level, prePCI fQRS at anterior localization and smoking (Table 2). 
Table 2. Univariable and Multivariable Regression Analysis for Predicting New-Onset or Persistance of fQRS after Primary $\mathrm{PCl}$

\begin{tabular}{|c|c|c|c|c|}
\hline & \multicolumn{2}{|c|}{ Univarible } & \multicolumn{2}{|c|}{ Multivariable } \\
\hline & OR $(95 \% \mathrm{CI})$ & $\mathbf{P}$ & OR $(95 \% \mathrm{CI})$ & $\mathbf{P}$ \\
\hline Pre-PCI fQRS at anterior localization & $2.01(1.74-2.55)$ & $<0.001$ & $1.51(1.24-1.74)$ & $<0.001$ \\
\hline $\mathrm{HDL}-\mathrm{C}, \mathrm{mg} / \mathrm{dL}$ & $1.14(1.07-1.21)$ & 0.012 & $1.03(0.91-1.12)$ & 0.128 \\
\hline $\mathrm{MBG}<3$ & $2.11(1.62-2.62)$ & $<0.001$ & $1.33(1.24-1.42)$ & $<0.001$ \\
\hline Smoking & $1.34(1.20-1.51)$ & $<0.001$ & $1.20(1.09-1.32)$ & 0.001 \\
\hline Peak CK-MB, U/L & $1.48(1.25-1.70)$ & $<0.001$ & $1.05(1.02-1.09)$ & 0.002 \\
\hline Age, years & $1.03(1.01-1.07)$ & 0.02 & $0.98(0.86-1.02)$ & 0.112 \\
\hline Angina-to-door time, hours & $0.67(0.57-0.78)$ & $<0.001$ & $0.78(0.65-0.95)$ & 0.015 \\
\hline TIMI frame count & $0.93(0.91-0.95)$ & $<0.001$ & $0.97(0.95-1.00)$ & 0.153 \\
\hline
\end{tabular}

$\mathrm{Cl}=$ confidence interval; $\mathrm{CK}-\mathrm{MB}=$ creatinine kinase-MB, fORS = fragmented ORS complex; HDL-C = high-density lipoprotein cholesterol; $\mathrm{MBG}=$ myocardial blush grade; $\mathrm{OR}=$ odds ratio; $\mathrm{PCI}=$ percutaneous coronary intervention; TIMI = thrombolysis in myocardial infarction.

\section{DISCUSSION}

In this study, we aimed to focus more on the association of MBG after primary PCI with evolution of $\mathrm{fQRS}$. We demonstrated that $\mathrm{MBG}<3$, CK-MB level, pre-PCI fQRS at anterior localization, and smoking were found as independent predictors of new-onset or persistence of fQRS after primary PCI and also number of leads with fQRS was negatively correlated with LVEF.

Twelve-lead ECG is the gold standard for immediate recognition of STEMI. ${ }^{19}$ Diagnosis of STEMI and assessment of the reperfusion can be performed via standard ECG changes which includes depolarization-repolarization abnormalities and ST-segment deviation. Among those changes the appearance of $\mathrm{Q}$ wave or new bundle branch block is the alteration of the depolarization which may be seen during MI course. ${ }^{20}$ Those signs may be transient or persist longer time. The fQRS which is identical to periinfarction block is also a depolarization abnormality and associated with myocardial scar. ${ }^{9,20-23}$ Das et al. ${ }^{24}$ showed that fQRS complexes on 12-lead ECG reflected the extent and location of ischemic or scar tissue in the ventricles. Indeed the presence of fractionated electrogram was delineated over myocardial scar teritories by endocardial or epicardial mapping whether the patients had ischemic or nonischemic etiology. $8,25-27$ Two separate studies by Das et al. ${ }^{9,11}$ investigated the sensitivity, specificity and negative predictive values of fQRS complex for myocardial scar. fQRS complex was found to have higher sensitivity and negative predictive value than $Q$ wave but less specific than $Q$ wave. ${ }^{9}$ In the other study fQRS was moderately sensitive but highly specific for myocardial scar and found to appear usually within 48 hours of acute coronary syndrome. ${ }^{11}$ Previous studies have demonstrated the association between perfusion defect, scar tissue, and fQRS. ${ }^{9-12,28}$ Perfusion abnormalities due to scar or ischemia are associated with a poor prognosis owing to the risk for ventricular arrhythmias and heart failure. $8,9,26,29$ fQRS was found to be associated or predictor of adverse cardiovascular events. Adverse events were shown in patients with coronary artery disease, ischemic cardiomyopathy and nonischemic cardiomyopathy. ${ }^{11,13,14,30,31}$

The restoration of epicardial blood flow can be assessed with TIMI flow grade in myocardial infarction. ${ }^{32,33}$ The rate of restoration is associated with clinical end points. ${ }^{34,35}$ The satisfactory restoration is defined as TIMI flow grade 3 that is accomplished in most of the patients who are treated with primary PCI. 4,5,36 On the other hand, regardless of restored epicardial blood flow, a considerable percentage of patients have impaired myocardial reperfusion and prognosis. ${ }^{37-39}$ Therefore, TIMI flow grade or well restoration of epicardial blood flow may not be sufficient for myocardial perfusion. MBG is a visual angiographic evaluation of myocardial perfusion that was first described by van't Hof et al. ${ }^{5}$ It is a simple way for assessment of myocardial perfusion. MBG provides additional information about microvascular bed. Microvascular bed is subjected to destruction during the course of MI that leads microvascular dysfunction and the necrosis of myocytes. The formation of microvascular dysfunction depends 
on the duration of the occlusion and the size of the myocardium supplied by the IRA and the quality of collateral circulation. ${ }^{40}$ Besides impairment of flow of the epicardial vessels, microvascular perfusion may be deteriorated by edema, inflammation, neurohormonal reflexes, vasoconstriction, and spontaneous or PCI induced embolization. ${ }^{39-41}$ Some studies demonstrated the association of MBG with ST-segment resolution, enzymatic infarct size, left ventricular function, and long-term mortality. ${ }^{4-7,42}$ Furthermore, a prospective study by Kampinga et $a{ }^{43}$ showed MBG as strong predictor of long-term mortality for patients who treated with primary PCI for STEMI.

In our study we have found that MBG was independently associated with new-onset or persistence of fQRS after primary PCI. Establishment of better microvascular circulation resulted in less perfusion abnormalities which might explain the resolution or absence of fQRS. Due to negative correlation between the number of leads with fQRS and LVEF, we have suggested that higher number of leads with fQRS reflects the extent of myocardial damage. Anterior localization of the fragmented leads on admission was also predicted the new-onset or persistence of fQRS at 48th hour. Greater myocardial area is under threat when left anterior descending artery occlusion occurs. We thought that despite optimal interventional procedure regarding time delay, some territories still remained insufficiently perfused or continuing stunning may be the reason of this finding. In addition, in line with previous studies, we observed a positive correlation of MBG with LVEF. Besides MBG, admission time to hospital predicted the presence of fQRS despite short door to balloon time. Myocardial cell death may be associated with fQRS as a consequence of late admission. Although all of our patients had ST-segment resolution after primary PCI, $32 \%$ of patients developed or had persisted fQRS. Accordingly, we speculate that ST-segment resolution could not define microvascular perfusion for all instances where fQRS may have urge. In cases where thrombolytic therapy is administered and sufficient ST-segment resolution occurs, the presence of fQRS may provide additional clinical information which should be tested with further studies.

Our study should be evaluated with some limitations. First one is the lack of data regarding long-term cardiovascular events (repeated revascularization, MI, and death) which is planned to be included in a future study. Second, myocardial perfusion was assessed only by conventional angiography in this study. Using other methods such as MR imaging and quantitative myocardial contrast echocardiography could have additional advantages.

In conclusion, despite complete ST-segment resolution in all patients, fQRS is independently associated with lower MBG as a marker of impaired microvascular myocardial perfusion. So, fQRS, as a simple and easily available noninvasive marker, may be useful in risk stratification of STEMI patients with increased extent of infarcted myocardium who underwent primary PCI.

\section{REFERENCES}

1. Armstrong PW, Collen D, Antman E. Fibrinolysis for acute myocardial infarction: the future is here and now. Circulation 2003;107:2533-2537.

2. Keeley EC, Boura JA, Grines CL. Primary angioplasty versus intravenous thrombolytic therapy for acute myocardial infarction: a quantitative review of 23 randomised trials. Lancet 2003;361:13-20.

3. Montalescot G, Ongen Z, Guindy $R$, et al. Predictors of outcome in patients undergoing PCI. Results of the RIVIERA study. Int J Cardiol 2008;129:379-387.

4. Haager PK, Christott $\mathrm{P}$, Heussen $\mathrm{N}$, et al. Prediction of clinical outcome after mechanical revascularization in acute myocardial infarction by markers of myocardial reperfusion. J Am Coll Cardiol 2003;41:532-538.

5. van 't Hof AW, Liem A, Suryapranata H, et al. Angiographic assessment of myocardial reperfusion in patients treated with primary angioplasty for acute myocardial infarction: myocardial blush grade. Zwolle Myocardial Infarction Study Group. Circulation 1998;97:2302-2306.

6. Stone GW, Peterson MA, Lansky AJ, et al. Impact of normalized myocardial perfusion after successful angioplasty in acute myocardial infarction. J Am Coll Cardiol 2002;39:591597.

7. Henriques JP, Zijlstra F, van 't Hof AW, et al. Angiographic assessment of reperfusion in acute myocardial infarction by myocardial blush grade. Circulation 2003;107:2115-2119.

8. Mahenthiran J, Khan BR, Sawada SG, et al. Fragmented QRS complexes not typical of a bundle branch block: a marker of greater myocardial perfusion tomography abnormalities in coronary artery disease. J Nucl Cardiol 2007; 14:347-353.

9. Das MK, Khan B, Jacob S, et al. Significance of a fragmented QRS complex versus a $\mathcal{Q}$ wave in patients with coronary artery disease. Circulation 2006;113:2495-2501.

10. Basaran $Y$, Tigen $K$, Karaahmet $T$, et al. Fragmented QRS complexes are associated with cardiac fibrosis and significant intraventricular systolic dyssynchrony in nonischemic dilated cardiomyopathy patients with a narrow QRS interval. Echocardiography 2011;28:62-68.

11. Das MK, Suradi H, Maskoun W, et al. Fragmented wide QRS on a 12-lead ECG: a sign of myocardial scar and poor prognosis. Circ Arrhythm Electrophysiol 2008;1:258-268.

12. Park SJ, On YK, Kim JS, et al. Relation of fragmented QRS complex to right ventricular fibrosis detected by late gadolinium enhancement cardiac magnetic resonance 
in adults with repaired tetralogy of fallot. Am J Cardiol 2012;109:110-115.

13. Das MK, Saha C, El Masry H, et al. Fragmented QRS on a 12-lead ECG: a predictor of mortality and cardiac events in patients with coronary artery disease. Heart Rhythm 2007:4:1385-1392.

14. Pietrasik G, Goldenberg I, Zdzienicka J, et al. Prognostic significance of fragmented QRS complex for predicting the risk of recurrent cardiac events in patients with Q-wave myocardial infarction. Am J Cardiol 2007;100:583-586.

15. Thygesen $\mathrm{K}$, Alpert JS, White HD, et al. Universal definition of myocardial infarction. Circulation 2007;116:2634-2653.

16. The Thrombolysis in myocardial infarction (TIMI) trial. Phase I findings. TIMI Study Group. N Engl J Med 1985;312:932-936.

17. Gibson CM, Cannon CP, Daley WL, et al. TIMI frame count: a quantitative method of assessing coronary artery flow. Circulation 1996;93:879-888.

18. Gibson CM, Cannon CP, Murphy SA, et al. Relationship of TIMI myocardial perfusion grade to mortality after administration of thrombolytic drugs. Circulation 2000;101:125130.

19. Antman EM, Cohen M, Bernink PJ, et al. The TIMI risk score for unstable angina/non- ST elevation MI: a method for prognostication and therapeutic decision making. J Am Med Assoc 2000;284:835-842.

20. Boden WE, Gibson RS, Schechtman KB, et al. ST segment shifts are poor predictors of subsequent $\mathrm{Q}$ wave evolution in acute myocardial infarction. A natural history study of early non-Q wave infarction. Circulation 1989;79:537548.

21. Alpman A, Guldal M, Berkalp B, et al. Importance of notching and slurring of the resting QRS complex in the diagnosis of coronary artery disease. J Electrocardiol 1995;28:199-208.

22. Corne RA, Parkin TW, Brandenburg RO, et al. Periinfarction block: postmyocardial-infarction intraventricular conduction disturbance. Am Heart J 1965;69:150-153.

23. Scherlag BJ, Gunn CG, Berbari EJ, et al. Peri-infarction block (1950)-late potentials (1980): their relationship, significance and diagnostic implications. Am J Cardiol 1985;55:839-841.

24. Das MK, Michael MA, Suradi $H$, et al. Usefulness of fragmented QRS on a 12-lead electrocardiogram in acute coronary syndrome for predicting mortality. Am J Cardiol 2009;104:1631-1637.

25. Wiener I, Mindich B, Pitchon R. Fragmented endocardial electrical activity in patients with ventricular tachycardia: a new guide to surgical therapy. Am Heart J 1984;107:8690.

26. Flowers NC, Horan LG, Thomas JR, et al. The anatomic basis for highfrequency components in the electrocardiogram. Circulation 1969:39:531-539.

27. Stevenson WG, Soejima K. Catheter ablation for ventricular tachycardia. Circulation 2007;115:2750-2760.

28. Homsi M, Alsayed L, Safadi B, et al. Fragmented QRS complexes on 12-lead ECG: a marker of cardiac sarcoidosis as detected by gadolinium cardiac magnetic resonance imaging. Ann Noninvasive Electrocardiol 2009;14:319-326.
29. Varriale $\mathrm{P}, \mathrm{Chryssos} \mathrm{BE}$. The RSR' complex not related to right bundle branch block: diagnostic value as a sign of myocardial infarction scar. Am Heart J 1992;123:369-376.

30. Maskoun W, Suradi H, Mahenthiran J, et al. Fragmented QRS complexes on a 12-lead ECG predict arrhythmic events in patients with ischemic cardiomyopathy who receive an ICD for primary prophylaxis. Heart Rhythm 2007;4:S211S212.

31. Michael M, Das M. Fragmented QRS (fQRS) on 12-lead EKG is a predictor of arrhythmic events and mortality in patients with dilated cardiomyopathy. Heart Rhythm 2006;3:S1-S3.

32. Chesebro JH, Knatterud G, Roberts R, et al. Thrombolysis in Myocardial Infarction (TIMI) Trial, Phase I: A comparison between intravenous tissue plasminogen activator and intravenous streptokinase. Clinical findings through hospital discharge. Circulation 1987;76:142-154.

33. The GUSTO Angiographic Investigators. The effects of tissue plasminogen activator, streptokinase, or both on coronary-artery patency, ventricular function, and survival after acute myocardial infarction. N Engl J Med 1993;329:1615-1622

34. Ndrepepa G, Mehilli J, Schulz S, et al. Prognostic significance of epicardial blood flow before and after percutaneous coronary intervention in patients with acute coronary syndromes. J Am Coll Cardiol 2008;52:512-517.

35. Simes RJ, Topol EJ, Holmes DR, Jr., et al. Link between the angiographic substudy and mortality outcomes in a large randomized trial of myocardial reperfusion. Importance of early and complete infarct artery reperfusion. GUSTO-I Investigators. Circulation 1995;91:1923-1928.

36. Grines CL, Cox DA, Stone GW, et al. Coronary angioplasty with or without stent implantation for acute myocardial infarction. Stent Primary Angioplasty in Myocardial Infarction Study Group. N Engl J Med 1999;341:1949-1956.

37. Niccoli G, Burzotta F, Galiuto L, et al. Myocardial no-reflow in humans. J Am Coll Cardiol 2009;54:281-292.

38. Roe MT, Ohman EM, Maas AC, et al. Shifting the open-artery hypothesis downstream: the quest for optimal reperfusion. J Am Coll Cardiol 2001;37:9-18.

39. Iliceto S, Marangelli V, Marchese A, et al. Myocardial contrast echocardiography in acute myocardial infarction. Pathophysiological background and clinical applications. Eur Heart J 1996;17:344-353

40. Kloner RA, Ganote CE, Jennings RB. The "no-reflow" phenomenon after temporary coronary occlusion in the dog. J Clin Invest 1974;54:1496-1508.

41. Hayat SA, Senior R. Myocardial contrast echocardiography in ST elevation myocardial infarction: ready for prime time? Eur Heart J 2008;29:299-314

42. Costantini CO, Stone GW, Mehran R, et al. Frequency, correlates, and clinical implications of myocardial perfusion after primary angioplasty and stenting, with and without glycoprotein IIb/IIIa inhibition, in acute myocardial infarction. J Am Coll Cardiol 2004;44:305-312.

43. Kampinga MA, Nijsten MW, Gu YL, et al. Is the myocardial blush grade scored by the operator during primary percutaneous coronary intervention of prognostic value in patients with ST-elevation myocardial infarction in routine clinical practice? Circ Cardiovasc Interv 2010;3:216-223. 